\title{
Experiencias de estudiantes de nivel superior en el marco de la pandemia: el tránsito de lo presencial a la enseñanza remota
}

Experiences of higher level students in the context of the pandemic: the transition from classroom to remote teaching

Gabriel Alejandro Álvarez Hernández 


\title{
Experiencias de estudiantes de nivel superior en el marco de la pandemia: el tránsito de lo presencial a la enseñanza remota
} Experiences of higher level students in the context of the pandemic: the transition from classroom to remote teaching

\section{Gabriel Alejandro Álvarez Hernández ${ }^{1}$}

\begin{abstract}
Resumen. El presente artículo es un informe de una investigación realizada con estudiantes de las licenciaturas en Pedagogía y Psicología Educativa de la Universidad Pedagógica Nacional Unidad 096 en la Ciudad de México en el marco de la pandemia provocada por el virus SARS-CoV-2 (COVID-19). Dicha pandemia ocasionó el traslado de cursos presenciales a cursos a distancia, de modo que el estudiantado que colaboró en esta investigación tuvo la experiencia de ese cambio de modalidad de forma emergente y sin una estrategia didáctica previa. Esto tuvo consecuencias de corte didáctico, puesto que la planta docente no tenía la formación pedagógica para trabajar a distancia y la comunidad estudiantil tampoco estaba capacitada ni tenía la experiencia. Para la realización de esta investigación se ocupó el enfoque cualitativo, la fenomenología hermenéutica como base epistemológica y el método biográfico narrativo. Por su parte, los instrumentos fueron cuestionarios por medio de formularios de Google y entrevistas por meet, que se aplicaron a un 80\% de la población estudiantil en el periodo de marzo a julio de 2020. Los resultados que se obtuvieron develaron que cada docente elaboró su propia estrategia para concluir los cursos, mientras que el estudiantado vivió múltiples formas derivadas de lo que cada docente le propuso. Lo anterior, entre otros factores, generó un ambiente de incertidumbre y confusión que alteró el curso de sus estudios. Se concluye con la necesidad elaborar estrategias pedagógicas que permitan un trabajo colegiado y homologado, de manera que los objetivos de aprendizaje se alcancen.
\end{abstract}

Palabras clave: universidad, estudiantes, experiencias de aprendizaje, pandemia.

Abstract. This article is a report of an investigation carried out with students of the degrees in Pedagogy and Educational Psychology of the National Pedagogical University Unit 096 in Mexico City in the framework of the pandemic caused by the SARS-CoV-2 virus (COVID-19). This pandemic caused the transfer of face-to-face courses to distance courses, so that the students who collaborated in this research had the experience of this change of modality in an emergent way and without a previous didactic strategy. This had didactic consequences, since the teaching staff did not have the pedagogical training to work remotely and the student community was neither trained nor had the experience. To carry out this research, the qualitative approach, hermeneutical phenomenology as an epistemological basis and the narrative biographical method were used. For their part, the instruments were questionnaires through Google forms and interviews by meet, which were applied to $80 \%$ of the student population in the period from March to July 2020. The results obtained revealed that each teacher elaborated their own strategy to complete the courses, while the student body experienced multiple forms derived from what each teacher proposed to them. The foregoing, among other factors, generated an environment of uncertainty and confusion that altered the course of their studies. It concludes with the need to develop pedagogical strategies that allow a collegiate and approved work, so that the learning objectives are achieved.

Keywords: university, students, learning experiences, pandemic.

\footnotetext{
${ }_{1}^{1}$ Universidad Pedagógica Nacional Unidad 096, Ciudad de México, México. Orcid https://orcid.org/0000-0001-6809-8321
}

Dirección electrónica: gabo.alvarezh@gmail.com

Artículo recibido: 18 de marzo, 2021

Enviado a corrección: 12 de julio, 2021

Aprobado: 23 de agosto, 2021 


\section{Introducción}

En el año 2020 se dio un fenómeno de proporciones mundiales que provocó un reacomodo profundo y general de las estructuras de cada nación, un hecho sin precedentes al menos en la historia reciente. La pandemia global provocada por el virus SARS-CoV-2 (COVID-19) o también conocido como Coronavirus se declaró el 20 de marzo de ese año por la Organización Mundial de la Salud.

Este fenómeno en México orilló a las autoridades a tomar decisiones y acciones para evitar que los efectos del virus fueran catastróficos tanto para la sociedad como para todos los sectores, el educativo no fue la excepción. En la Universidad Pedagógica Nacional (UPN) de este país, antes de que el virus fuera una realidad, se desarrollaban las clases presenciales con normalidad: las aulas, la planta docente y estudiantes de los distintos programas educativos llevaban a cabo las tareas educativas con regularidad, esto hasta que la máxima autoridad de la UPN ordenó el cierre total de las instalaciones.

Por otra parte, los medios de comunicación anunciaban que las autoridades ordenaban el cierre de todo espacio que conglomerara gente, esto para evitar, o al menos para frenar, una fuerte propagación del virus, de manera que los cursos en cuestión tuvieron que trasladarse a ambientes y medios virtuales. Mientras lo medios masivos de comunicación manejaban indistintamente términos como "Enseñanza virtual" o "Enseñanza en línea", etcétera, pero para Niño, Castellanos y Patrón (2021) el concepto de Enseñanza remota es el que mejor define a una adaptación forzada de programas educativos presenciales y su traslado improvisado a plataformas tecnológicas (p. 2) y es el que se ocupa en este trabajo.

En la misma línea de tiempo, a inicios de la pandemia en el 2020, se realizó una investigación que exploró las experiencias de estudiantes en estos cursos que fueron de modalidades presenciales a enseñanza remota (Álvarez y De la Riva, 2021), en este se encontró que el mayor reto que el estudiantado vivió fue la falta de recursos tecnológicos para llevar a cabo sus estudios en plataformas tecnológicas, pues esta población es de escasos recursos y cuyas familias tienen fuentes de ingresos muy limitadas e inestables y que por la misma pandemia se vieron perjudicadas, algunos de los testimonios del estudiantado sobre la dificultad de llevar a cabo sus estudios afirman:

Es un poco difícil, ya que solo existe una laptop en casa y es utilizada para trabajar y estudiar por tres personas dentro del hogar.

Me cuesta realizar presentaciones, o hacer algunos trabajos debido a que necesito Word y se necesita pagar una licencia. 
Mi dispositivo móvil a veces no tiene la capacidad o velocidad que demandan las aplicaciones que se requieren.

Mi computadora tiene algunas deficiencias como que tiene que estar conectada todo el tiempo ya que la batería no sirve, se tarda en prender.

No soy la única en casa que necesita ocupar los aparatos, cuesta más trabajo acomodar horarios, no solo para realizar trabajos, también para tomar clases

No cuento con los dispositivos más nuevos y actuales por lo cual a veces tenía problema con la capacidad de memoria, en ocasiones son lentos o se llegan a trabar y conexión de internet no siempre es la mejor.

No contaba con una computadora ni Internet para estar en clases en línea y entregar trabajos.

Tenía una laptop que hacía que las clases en línea fueran más sencillas, pero se me descompuso, entonces todo tenía que hacerlo en el celular, por esa razón me fue difícil.

Para mi ha sido muy difícil ya que debido a la situación quienes apoyan económicamente en mi casa se quedaron sin trabajo lo cual repercutió en que nos quedáramos sin internet y sin las cosas esenciales para poder enviar mis tareas.

Ha sido difícil, dado que no cuento con los recursos tecnológicos y por las circunstancias, ha sido complicado encontrar algún café internet abierto.

En un análisis que realiza Germán Álvarez Mendiola, presidente del Consejo Mexicano de Investigación Educativa (COMIE) y Jefe del Departamento de Investigaciones Educativas (DIE) de Instituto Politécnico Nacional (IPN), aborda el problema de la brecha digital que hay en el país, pues con datos del Instituto Nacional de Estadística y Geografía (INEGI), se estima que el $60 \%$ de los hogares en México no cuentan con al menos una computadora, lo que consecuente en un problema de acceso a la enseñanza remota por parte del estudiantado (Álvarez, 2020).

Posteriormente en la investigación que dio inicio a este informe, otro elemento problematizador que surgió de los testimonios del estudiantado² fue uno que versaba sobre la actividad propia de la enseñanza remota, la cual tuvo como premisa la improvisación en la adaptación de los cursos presenciales a ambientes virtuales, a plataformas electrónicas. El

\footnotetext{
2 Dichos testimonios son los que dan cuerpo a la Unidad de Análisis central de este informe, de manera que los relatos se exponen en el apartado de los Resultados.
} 
presente manuscrito da cuentas de las vicisitudes, las incidencias y las complejidades de la enseñanza remota en esta institución, esto desde la voz del estudiantado.

Para la realización de la investigación, se propuso como objetivo general comprender las experiencias del estudiantado en el tránsito de sus estudios presenciales a la enseñanza remota, a partir de un estudio fenomenológico y hermenéutico, con el fin de identificar las problemáticas de este fenómeno. Consecuentemente la pregunta de investigación inicial fue ¿Cómo vivió el estudiantado de las licenciaturas en Pedagogía y en Psicología Educativa de la UPN Unidad 096 el tránsito de sus cursos presenciales a una enseñanza remota y la culminación de estos?, pregunta que corresponde a planteamientos epistemológicos de la fenomenología hermenéutica de Van Manen, es decir "La fenomenología pregunta: «¿Cómo es tal o cual tipo de experiencia?»" (2003, p. 27).

\section{Referente teórico}

El concepto experiencia de Larrosa (2003) fue clave para este trabajo, el cual deja de manifiesto que las experiencias no son lo que pasa, sino lo que nos pasa, aquello que en su referencia práctica permite valorar lo vivido como un aspecto desde lo más profundo del o la protagonista de la experiencia, como ese momento que queda en la historicidad de cada quien y que es principio de un devenir, de una transformación de la persona. La experiencia, eso que pasó, es principio y dispositivo del sujeto en su formación, en su andar y vivir los actos educativos, las situaciones y contingencias que en suma van dando cuerpo a fenómenos que incorporan componentes vitales y de relaciones intrapersonales pero además con relación a la otredad; en esa dinámica la experiencia abre un campo de reflexión en el que los saberes, los saberes de la experiencia, se conjugan en un pozo hondo de sabiduría que transforma y posiciona contundentemente a quien vive o vivió la experiencia concreta.

Experiencia y saber son conceptos clave, unidos e implicados de un modo dinámico e indisoluble para quien los incorpora, el saber no se deshace de la experiencia y en su análisis se encuentran sus relaciones y muestran aspectos prácticos y profundamente vitales de los fenómenos educativos. La educación como un hecho concreto y vivido se sostiene, entre otras cosas, desde un saber o saberes, estos allanados en la experiencia y la experiencia se enriquece de esta dinámica, un saber que se destaca por su refrendo al mundo de la vida y que se niega a ascender al «cielo de la objetividad» (Alliaud y Suárez, 2011).

Para la realización de esta investigación se tuvo como personajes centrales al estudiantado de las licenciaturas en Pedagogía y Psicología Educativa, se recoge el concepto 
de estudiante que Pérez de Lara (2011) expone como "[...] aquellas alumnas y alumnos que desde sus modos de estar en el mundo la cuestionan -a la pedagogía-, porque hacen tambalear sus principios con su sola presencia en las aulas" (p. 47). Así, alumnas y alumnos con sus relatos, sus experiencias, abren el campo de reflexión que permitió la elaboración de este informe.

Las y los estudiantes que colaboraron para esta investigación, su vivir el fenómeno educativo aquí expuesto, lo hacen con relación a otros y otras, es decir que lo vivido no es una experiencia que se da o se dio en el ensimismamiento, sino que tuvo alteraciones (de alteridad) a partir de su encuentro y desencuentro tanto con la comunidad que conforma su escenario educativo como con un contexto amplio y general que se matizó por la pandemia global, de modo que la alteridad fundamenta e impulsa una panóptica que exige recuperar las relaciones interpersonales así como con el contexto (Skliar y Larrosa, 2009).

En este trabajo, cada estudiante fue sujeto central para poder comprender el fenómeno educativo circunscrito en el marco pandémico y que al menos en la primer mitad del 2020 fue singularmente desconcertante para la comunidad educativa, pues en sus relatos, sus historias de vida en ese momento marcado por la contingencia y la emergencia, lleva a la reflexión de que las experiencias de cada estudiante no están solamente al margen de lo que se vivió en el espectro de la institución educativa, sino que un escenario amplio y global se involucra profundamente, incluso otras personas, otras relaciones interpersonales fuera de la escuela pero implicadas con la formación de cada estudiante, son insumo para la comprensión en este trabajo, en palabras de Delory-Momberger: "La narrativa autobiográfica instala una hermenéutica de la "historia de vida", es decir, un sistema de interpretación y de construcción que sitúa, une y da significado a los acontecimientos de la vida como elementos organizados dentro de un todo." (2009, p.59).

La narrativa tuvo presencia en la elaboración de esta investigación, pues ésta abre las reflexiones a aspectos que centran a la persona que está en el foco de un fenómeno de la vida; la narración, dice Bruner, "[...] modela no solo un mundo, sino también las mentes que intentan darle sus significados." (2002, p. 49); así, la narrativa fue parte fundamental de esta investigación, pues es congruente con la hermenéutica toda vez que supone que las personas son esencialmente escritores de los relatos de sus vidas (Bolívar, Domingo y Fernández, 2001, p. 21).

Por último, las experiencias del estudiantado que aquí se recuperan, están en el marco de una educación que -como ya se mencionó- se tuvo que adaptar a plataformas tecnológicas, 
de modo que hay que precisar cómo es que se manifiesta desde el punto de vista conceptual este fenómeno, y el concepto fue el de enseñanza remota de emergencia el cual su objetivo es "[...] más que recrear un sistema de formación en línea en medio de la crisis, es suavizar la brecha de aprendizaje entre los estudiantes a través de la utilización de recursos tecnológicos, mientras se resuelve la incidencia." (Niño et al., 2021, p. 3).

\section{Metodología}

Para llevar a cabo la presente investigación, se tomó como tradición filosófica base para el concepto de ciencia la Aristotélica (Mardones y Ursua, 1995), pues a partir de ésta se pone como conceptos centrales a la subjetividad, interpretación, historicidad, sociedad, cultura, experiencia, saberes, sentidos y significados entre otros, y que en su composición dotan de cientificidad a trabajos como el presente, cuyo objetivo epistemológico fundamental es la comprensión (Vertehen); por su parte y consecuentemente, el paradigma que se recuperó fue el interpretativo, el cual dio bases epistemológicas, ontológicas y metodológicas (Álvarez, 2019) que vertebraron el trabajo metodológicamente.

Consecuentemente, la fenomenología hermenéutica brinda los componentes epistemológicos plataforma para el aparato metodológico de esta investigación, reconoce que la educación al ser una actividad profundamente humana y constituida por inquietudes e impulsos vitales, adhiere una concepción de ciencia humana y reflexiva que en palabras de Van Manen:

Al trasladar a la conciencia reflexiva la naturaleza de los acontecimientos experimentados en nuestra actitud natural, podemos transformarnos o rehacernos, en el sentido auténtico del Bildung (formación). La investigación fenomenológica hermenéutica edifica la percepción personal [...] con lo que contribuye a la afirmación del propio carácter reflexivo y a la capacidad de uno mismo para actuar por y para los demás, niños o adultos, con tacto o discreción. En este sentido, la investigación en ciencias humanas es en sí misma un tipo de bildung o paideia; es decir, el currículo del ser y el devenir. Podríamos decir que la fenomenología hermenéutica es una filosofía de lo personal, de lo individual, que ejercemos contra un conocimiento previo del carácter evasivo del logos del «otro», el «todo», lo «común» o lo «social». (2003, p. 25) 
Para el referente epistemológico que sirvió de plataforma y marco de referencia la fenomenología porque describe el modo en que cada sujeto se arroja hacia la experiencia vivida; por su parte, la hermenéutica acentúa las interpretaciones de cada quien sobre los «textos» de la vida (Van Manen, 2003, p.22). En el mismo texto, Van Manen invita a pensar los escenarios educativos como espacios en los que las prácticas educativas, en esta investigación las que involucran al estudiantado en todos los sentidos, sean vividas como experiencia, es decir, que abran a la reflexión y análisis con relación al mundo de la vida de cada cual, que lo que se aprenda sea vivido, incluso imaginativamente, de modo que adquiera un sentido y significado y que esto provoque un cambio o transformación del sujeto de la educación.

La fenomenología hermenéutica, además, destaca de manera central que los fenómenos educativos son acciones vividas, subjetivamente vividas, esas subjetividades piensan y vuelven a pensar los fenómenos en el horizonte de la historia de vida personal, los aspectos contextuales que conciernen a quien protagoniza y sus perspectivas y expectativas proyectadas, de modo que en la vivencia de los fenómenos las experiencias develan los caminos y los modos en los que se construyeron los significados y los sentidos en la formación del estudiantado.

\subsection{Enfoque}

El enfoque fue el cualitativo (Maykut y Morehouse, 1999), porque desde sus postulados se abre la posibilidad de una comprensión del fenómeno vivido, en su contexto y dimensión humana por medio de la observación minuciosa de las palabras, relatos y demás datos de la experiencia. Este enfoque centra a la comprensión como fundamento para aprehender sentidos y significados propios de las personas estudiadas, en este caso del estudiantado universitario, éste además considera que cada individuo es parte del mundo que habita y viceversa, en una relación dinámica, constante e inacabada.

El método fue el biográfico-narrativo (Bolivar et al., 2001) porque da los planteamientos puntuales de un quehacer investigativo que centra a la persona y sus narraciones, en éstas, cada estudiante que colaboró manifestó en relatos maneras y episodios con los que construyeron sus sentidos y significados con relación al fenómeno vivido, de modo que el lenguaje es el medio por el cuál las experiencias se expresan y se manifiestan y permiten acceder a los componentes de un mundo permeado por la pandemia en voz de estos y estas protagonistas: 
Diversos elementos configuran la narrativa como una racionalidad sustentadora de procesos educativos, formativos, pedagógicos e investigativos en los ámbitos de las ciencias sociales y humanas. Enfoque investigativo, técnica de recolección de datos, instrumento para recoger información, dimensionan aspectos metodológicos que relacionan la narrativa con la investigación, por una parte; construcción de realidad, expresión de la vida y la identidad, dimensión performativa, por otra parte, determinan un contenido epistemológico de la narrativa vinculado con procesos formativos. La integración de los aspectos metodológicos y epistémicos permite considerar la narrativa como una racionalidad que no sólo se relaciona con asuntos de la vida humana (episteme), uno de los cuales es la educación, sino que ofrece la posibilidad de una metodología para abordarlos y reconfigurarlos de manera científica (meta-dos). (BarriosTao, 2018, p. 480)

En síntesis, la tradición filosófica que subyace al trabajo en su fundamento científico es el Aristotélico por su componente epistemológico que propone como propósito la comprensión (Versthen); el enfoque cualitativo dado que en so configuración propone conceptos que en suma dan las pautas metodológicas para un trabajo de investigación que se enfoca en fenómenos humanos y sociales como lo es la educación; por último el método biográficonarrativo porque agrega temática y metodológicamente claves para un trabajo que centra la experiencia vivida sustantivamente.

\subsection{Unidades de análisis}

El presente informe de investigación y las consecuentes unidades de análisis tuvieron como inicio un vagabundeo sobre lo que la comunidad estudiantil el cual "Supone un acercamiento de carácter informal, incluso antes de la toma de contacto inicial, al escenario que se realiza a través de la recogida de información previa del mismo: qué es lo que caracteriza, especto exterior, opiniones, características de la zona y el entorno, etc." (Rodríguez, Gil, y García, 1996, p. 72), el vagabundeo se dio a partir de un formulario de Google que se aplicó al $80 \%$ de la comunidad estudiantil de las licenciaturas en Pedagogía y Psicología Educativa de un total de 161 que componen la matricula, este porcentaje fue al que se pudo acceder, el resto fueron estudiantes que dada la pandemia y por razones personales se distanciaron de la institución. 
La población con la que se trabajó fue la que correspondió con programas de estudios de licenciaturas que son semestrales, puesto que otros programas educativos de la UPN no lo son (por ejemplo hay bimestrales y trimestrales), y al ser semestral permite reconocer una experiencia que abarca más tiempo y por lo tanto la experiencia se enriquece, lo que deriva en conclusiones y datos de relevancia pedagógica y didáctica con mayor consistencia; también, fue porque sus estudios presenciales fueron cortados a la mitad de sus cursos y se trasladaron emergentemente a ambientes virtuales a una enseñanza remota; posteriormente y como parte del vagabundeo y análisis de la información que se recogió, fue que se concluyó que los recursos con los que contaban y las estrategias que el profesorado desarrolló en este contexto fueron elementos de selección por su recurrencia en cada estudiante, en sus respuestas.

Posteriormente al vagabundeo, se aplicó un segundo cuestionario por formularios de Google y que dio referentes empíricos clave que llevaron a dos unidades de análisis definidas: la primera asociada con las condicione económico-sociales, la segunda recupera aspectos pedagógicos y didácticos, a continuación la Tabla 1 sintetiza: 
Tabla 1.

Unidades de análisis y sus componentes

\begin{tabular}{|c|c|}
\hline $\begin{array}{l}\text { Condiciones económico-sociales del } \\
\text { estudiantado para la enseñanza remota. }\end{array}$ & $\begin{array}{l}\text { Condiciones pedagógico-didácticas del } \\
\text { estudiantado para la enseñanza remota. }\end{array}$ \\
\hline $\begin{array}{l}\text { - Se trasladan a otros lugares, casas, } \\
\text { municipios, estados. } \\
\text { - No tienen los recursos o los perdieron en el } \\
\text { proceso por descompostura o por falta de } \\
\text { mantenimiento o pago: computadora, } \\
\text { laptop, smartphone; las Apps; acceso a } \\
\text { Internet, etcétera. } \\
\text { Tienen que trabajar para solventar los } \\
\text { gastos familiares. } \\
\text { - Son cuidadores de menores de edad o de } \\
\text { personas vulnerables. } \\
\text { Existen familiares que apoyan prestando } \\
\text { computadora, red y vivienda a los } \\
\text { estudiantes. } \\
\text { Hay estudiantes enfermos de CoviD-19 o } \\
\text { con familiares enfermos que afectan la } \\
\text { organización familiar. } \\
\text { En las estudiantes se generan } \\
\text { expectativas, sentimientos, emociones } \\
\text { respecto a la situación, el grupo al que } \\
\text { asisten y los profesores no los apoyan en } \\
\text { estos aspectos. } \\
\text { El tiempo para el uso de los recursos es } \\
\text { poco y no tiene horario fijo por las } \\
\text { condiciones en las que viven. }\end{array}$ & $\begin{array}{l}\text { - No se sabe con qué recursos cuentan las } \\
\text { alumnas y alumnos, utilizan aplicaciones (Apps) } \\
\text { que requieren hardware sofisticado } \\
\text { - Se impone el tipo de App o software sin tomar } \\
\text { en cuenta si el alumnado puede acceder a ésta, } \\
\text { porque requieren una cantidad de datos o } \\
\text { acceder a buen internet } \\
\text { - Se impuso horarios y duración de las sesiones } \\
\text { sin tomar en cuenta las condiciones y recursos, } \\
\text { no flexibilizaron o fueron claros, sino que se } \\
\text { asignó la necesidad de asistir en tiempo real a } \\
\text { las sesiones virtuales } \\
\text { No adecuan la estrategia ni las secuencias } \\
\text { didácticas de sus cursos a una lógica de trabajo } \\
\text { en línea. Repiten la dinámica de las clases } \\
\text { presenciales } \\
\text { No toman en cuenta que hay estudiantes que } \\
\text { apoyan a otros estudiantes con menos } \\
\text { recursos, no fomentan la organización entre } \\
\text { ellos, no trabajan con grupos de tamaño } \\
\text { adecuado al hardware y software y a lo que se } \\
\text { va a hacer (construcción de conceptos, } \\
\text { discusión, conclusiones, evaluaciones) } \\
\text { No toman en cuenta que el estudiantado tiene } \\
\text { sentimientos y emociones que afectan en el } \\
\text { transcurso de sus cursos, carecen de un } \\
\text { colegio donde se hable de estos asuntos } \\
\text { No utilizan herramientas para trabajar con los } \\
\text { alumnos rezagados o con pocos recursos o } \\
\text { menos sofisticados: teléfono fijo, drive y correo, } \\
\text { grupos de Facebook, etc. }\end{array}$ \\
\hline
\end{tabular}

Fuente: elaboración propia con información de los resultados de los formularios de Google, 2021

De manera central las unidades de análisis y sus componentes arriba expuestos fueron parte de la problemática del primer semestre del 2020 para la enseñanza remota, para este informe se recupera la que se tituló Condiciones pedagógico-didácticas del estudiantado para la enseñanza remota. Por su parte, la primera Unidad titulada Condiciones económico-sociales del estudiantado para la enseñanza remota sus hallazgos ya fueron publicados (Álvarez y De La Riva, 2021). La decisión de hacer un artículo por unidad de análisis se dio porque cada una tuvo orientaciones peculiares, aunque relacionadas, y porque el dato empírico que les daba sustento era demasiado como para un solo artículo. 
Acto seguido se eligieron a estudiantes cuya experiencia diera manifiesto claro de las unidades de análisis, la selección de los informantes a entrevistar fue porque en sus respuestas al cuestionario narraron con profundidad experiencias que se articulaban de un modo directo y fehaciente con ambas unidades de análisis, se entrevistaron vía Google meet con un guion de entrevista conversacional (Van Manen, 2003). En el siguiente punto se describen las técnicas de recolección de datos.

\subsection{Técnicas de recolección de información}

Los cuestionarios que se realizaron y aplicaron fueron por medio de formularios de Google, de modo que se pudo prescindir literalmente de la presencial del investigador con el estudiantado, los correos electrónicos y los grupos de WhatsApp ayudaron al quehacer de campo. El primer cuestionario tuvo como elemento metodológico central preguntas abiertas y cerradas que tenían la intención de identificar las problemáticas centrales del estudiantado, además de preguntarles datos como nombre, semestre, licenciatura y edad (Ver Anexo 1: Preguntas primer cuestionario).

Con las respuestas se procedió a analizarlas, una por una, hasta llegar inductivamente a la identificación de dos componentes centrales y problemáticos en la experiencia del estudiantado: Los recursos tecnológicos para poder atender sus clases en línea en la enseñanza remota y el papel del profesorado y sus estrategias para concluir los cursos que comenzaron presenciales y terminaron en enseñanza remota. Con la información se construyó un segundo cuestionario, con preguntas orientadas a los dos componentes mencionados (Ver Anexo 2: Preguntas segundo cuestionario).

Luego de que se procesó y analizaron inductivamente las respuestas a las preguntas anteriores, se terminó por definir y consolidar las unidades de análisis ya comentadas. De estas respuestas se seleccionó a las y los estudiantes que en sus respuestas fueron descriptivos y que además mostraron relación directa con las problemáticas centrales, se les aplicó una entrevista conversacional (Ver Anexo 3: Guion de entrevista conversacional) a cuatro estudiantes vía Google meet.

Con los dos cuestionarios y las entrevistas conversacionales contestadas, se transcribieron tanto en hojas de cálculo como en un procesador de palabras, Microsoft Excel y Word respectivamente, y se procedió al análisis e interpretación de los datos y se describe a continuación en el siguiente punto. 


\subsection{Procesamiento de análisis}

La tercera etapa propiamente consistió en la sistematización, análisis e interpretación del dato empírico, de las experiencias de cada estudiante, para esto se ocupó el tipo de lectura holístico de la forma $(\mathrm{H}-\mathrm{F})$ que "[...] encuentra su mejor expresión en la búsqueda de la trama o estructura global de una historia de vida: por ejemplo, la progresión, declive o estabilidad de una trayectoria desplegada en la trama del relato" (Bolívar et al., 2001, p. 192). Para la construcción de los relatos se combinaron dos posturas, la restitutiva o hiperempirista y la analítica y de reconstrucción del sentido (Bolivar et al.,2001, pp. 199-202). La primera respeta el discurso del protagonista de manera fiel tanto como sea posible, sin alterar lo relatado; la segunda, porque de las narrativas se extraen fragmentos que en una secuenciación inductiva logren dar cuentas del fenómeno vivido.

Para poder procesar, analizar e interpretar el dato empírico, se ocupó las posibilidades que ofrece Google con sus formularios y también paquetería básica como Microsoft Excel y Word, de modo que inductivamente ésta se ordenó, sistematizó y sobre todo se interpretó desde los planteamientos teóricos de la fenomenología hermenéutica, la experiencia vivida, la narrativa, sentidos y significados, de modo que progresivamente se avanzó en esta etapa hasta llegar a las interpretaciones y resultados aquí expuestos, en el horizonte de la comprensión (Verstehen). Por último, se prosiguió a elaborar el informe y que se expone en el siguiente apartado.

\section{Resultados}

Los resultados luego de ser sistematizados y analizados se encontró que tres elementos fueron los que tuvieron una relación manifiesta y directa con la experiencia del estudiantado, el primero fue el reconocer que la enseñanza remota no era tarea sencilla, que mucho tenía que ver tanto los recursos y la dinámica de trabajo con cada docente, así como la preparación pedagógica que se tuviera o no; el segundo tuvo implicación al acercamiento y tiempo que la planta docente tuvo con sus respectivos grupos, se indagó qué tanto se acercaba el profesorado y se encontró la siguiente frecuencia (Ver Figura 1); el tercero fue que los pares del estudiantado jugó también un papel decisivo en esta experiencia. 
Figura 1.

Porcentaje de estudiantes que indican el nivel de frecuencia con respecto al acercamiento con el profesorado, UPN - México, 2020
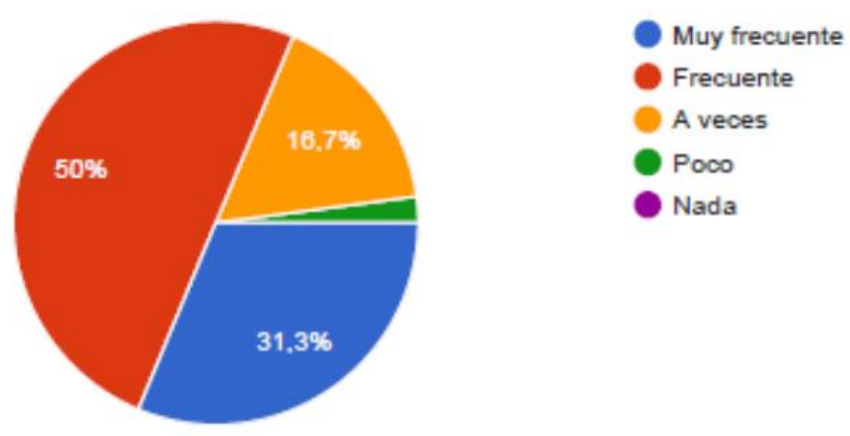

Fuente: Elaboración propia con información de segundo cuestionario, 2021

El estudiantado, en su experiencia, fue preciso e incisivo con el acercamiento que cada docente tuvo con cada uno de sus grupos, esto manifiesta que en las relación entre estas dos figuras el acompañamiento es un elemento clave en el desarrollo y conclusión de los cursos, así como en lograr los objetivos de aprendizaje; dada las características del contexto pandémico y que requirió traslado urgente e inmediato de modalidad presencia a una enseñanza remota, además de la incertidumbre y miedo que se generó, el estar en constante comunicación permitió que esta experiencia fuera mejor llevada, como comenta Skliar (2020) "Para que existan historias, para que puedan ser contadas de verdad, en su duración imprecisa y en un lugar indefinido, es necesario escuchar, y esto quiere decir: prescindir del yo que se anticipa, que ya sabe, que ya conoce, que adivina aburridamente lo que vendrá." algunos testimonios recuperados de los cuestionarios dicen ${ }^{3}$ :

Los profesores se interesan por el bienestar y el aprendizaje de todos sus alumnos, desde que inicia las clases preguntando cómo han pasado todo esto y haciendo que participen con ejemplos

En su mayoría los profesores que tuve fueron conscientes de la situación en la que nos encontramos y se detenían un poco más para explicar algún tema o duda

No todos nos daban clases, algunos profesores solo pedían trabajos y de otros no tuvimos contacto para nada desde que salimos

\footnotetext{
${ }^{3}$ Los testimonios del alumnado se exponen tal cuál fueron escritos o relatados, de modo que el lenguaje inclusivo no se expresa en la totalidad deseada (N. del A.) 
Los profesores buscaban los medios para mantenerse comunicados con nosotros, algunos eran muy atentos y preguntaban cómo estábamos emocionalmente y otros profesores se limitaban a informar sobre la escuela y explicarnos claramente los temas para poder hacer los trabajos

Mis profesores son muy pacientes y amables, pero no todos explican muy bien sus clases ni son muy frecuentes a platicar con nosotros más allá del tema escolar

Estuvieron muy al pendiente de nosotros, no solo académicamente, también psicológicamente. Siempre nos preguntaban cómo íbamos llevando esto.

Parte del quehacer docente es llevar tanto la explicación de los temas y al grupo a su entendimiento, además tener el tacto y sensibilidad para mantener un ambiente propicio para el aprendizaje, esto lleva en ocasiones tener que dedicar tiempo a escuchar, a preguntar por el estado de ánimo y mostrar interés, toda vez que el acto educativo tiene matices humanos y de interacción con el otro, de alteridad en palabras de Skliar y Larrosa (2009), el tacto y la sensibilidad (Van Manen, 1998) son también componentes pedagógicos que contribuyen y determinan hasta cierto punto el quehacer docente y las relaciones con sus estudiantes.

Cada profesor y profesora en el contexto de ese primer semestre del 2020, y que la pandemia llevó inesperadamente a la reconfiguración de las clases, tuvo que encontrar la manera de comunicarse con sus estudiantes y llevar a cabo las clases, aunque como se mencionó el aspecto emergente e inesperado de la pandemia dificultó la actividad educativa, los siguientes relatos exponen 4 :

No todos los maestros ni todos los alumnos estábamos preparados para esta situación, en mi caso en mi salón había compañeros que son mucho mayores que yo, tengo una compañera de casi 50 años que está tomando clase. Hubo un caso en específico que la clase se volvía muy tediosa dado que no sabía utilizar las herramientas. Cuando esto cambia a ser una clase a distancia pues era más complicado porque hacíamos un foro y comentábamos sobre lecturas como súper enormes y era difícil participar porque todas opinábamos y el profesor nada más como que decía «si está bien gracias por sus aportes de hoy» y te explicaba cosas de la clase antepasada (I1)

\footnotetext{
${ }^{4}$ Los relatos derivados de las entrevistas se expresan con la nomenclatura I1 para la Informante 1, I2 para la Informante 2 y así consecutivamente con cada entrevista.
} 
También creo que no estamos preparados ni aptos para tomar clases en línea, porque creo que todos o la mayoría de los estudiantes estamos acostumbrados a ir a una escuela de manera presencial, nunca hemos trabajado en línea y yo lo vi en mí, mis primos y mis hermanos que no funcionaba; de hecho mandaban algo y yo necesito que me lo expliquen, que me digan "oye vas a hacer esto y eso», entonces no estamos preparados para llevar clases en línea. (I3)

Ni profesores ni nosotros teníamos un plan para que esto pasara, no contábamos con temas determinados; luego la otra parte que es la personal, en mi casa compartimos un internet para todos, nada más contamos con una computadora que ahorita estoy ocupando y nada más es una, y pues la ventaja que tuve con mi hermano pequeño es que él tomaba clases en línea en la mañana porque él va en la mañana, el problema lo encontré con mi hermano mediano porque también estudia en la tarde, entonces nuestras clases, nuestros horarios se cruzaban y pues en los momentos de tomar clases era difícil. (I2)

Algunas de las experiencias expuestas por estudiantes confirmaban contrastes y comparaciones entre la educación presencial y la enseñanza remota, donde la primera se privilegia sobre la segunda. Los relatos expresan la dificultad de estudiar bajo estrategias en plataformas virtuales como lo es un foro de discusión, en estos las argumentaciones y debates con relación a un tema se vive con carencia, sobre todo cuando se compara con una dinámica similar pero de manera presencial en la cual el tiempo fluye a un ritmo distinto y las interacciones con los demás son al momento; también se devela que la presencia y la comunicación verbal que se da de manera natural al estar cara a cara se reconoce como una actividad mejor y que disipa dudas claramente, lo que de modo virtual no se logra del todo.

Por otra parte, los tiempos y las actividades de cada quien se modificaron sustancialmente, mientras para unos los recursos con los que se cuentan se tienen que dividir entre dos o más miembros de la familia, en otros casos simplemente el tener que estudiar los temas de manera asíncrona y por plataformas desconocidas era ya un reto difícil de superar.

En las interacciones, en esa visión de lo educativo en el que se logran de manera directa o indirecta asociaciones, surgen las figuras de los pares como apoyo y ayuda; algunas de las experiencias muestran que estudiantes en esta experiencia encontraron en compañeras o compañeros la respuesta a algunas de sus inquietudes con sus estudios, a continuación se exponen algunos relatos: 
Casi diario yo le marcaba a mi compañera, porque soy una persona a la que le tienen que decir todo bien, o sea explicar bien, entonces pues yo le comenté a ella que se me estaba dificultando mucho porque no entendía, por más que leía no entendía entonces yo le dije «¿me podrías hacer el favor de explicarme las tareas? Así sea lo más tonto o lo más entendible así explícamelas así sea» me decía "Oye tú vas a hacer esto y esto...», entonces diario hablábamos, entonces ya me decía "es esto o así» y yo le agradecía mucho (14)

Mi compañera también tenía un problema con su computadora, su mamá es mamá soltera y se hace cargo de su hermano, entonces su mamá depende de una estética, entonces entró el problema que no tiene trabajo entonces, mi amiga a veces me escribía y me decía «hoy no tengo dinero y nos van a cortar el internet ¿qué voy hacer?» y yo le decía «no te preocupes, yo te puedo marcar y te puedo decir qué dejaron de tarea, y si necesitas crédito yo le digo a mi mamá que te ponga, o yo te pongo, o me mandas tu tarea y yo le explico al profe, o tú me marcas o yo te marco.»

Algunas de las experiencias de estudiantes narran cómo las dificultades derivadas de múltiples aspectos provocaban que tuvieran que recurrir al apoyo de sus pares, las tareas, la falta de recursos, así como otras complicaciones hicieron de la actividad del estudio un hito sinuoso y con dificultades, pero encontraban en alguien el apoyo que les hacía falta para lograr concluir con sus cursos.

Como parte del trabajo de campo también se recuperó en el cuestionario lo que para cada estudiante podría hacerse para mejorar sus clases, la pregunta literalmente fue “¿Qué podrías sugerir para mejorar tu experiencia pedagógica en este contexto de las clases $A$ Distancia?", a continuación algunas respuestas:

Que todos los profesores se comprometieran de la misma forma y buscarán la mayor cantidad de alternativas posibles para impartir el conocimiento

Que los alumnos participen más, poner más empeño en la atención a la clase y que los profesores no solo pongan a leer, que hagan dinámicas para casa

A mi parecer esta excelente el sistema que manejaron los profesores

Qué haya una mejor retroalimentación, en vez de pedir trabajos tengamos clase; el encierro provoca muchos problemas de ansiedad, debemos ser conscientes de que los trabajos estresan mucho 
Que se tengan clases por zoom es un medio muy práctico y el aprendizaje es muy parecido al presencial

Pues la utilización de las herramientas digitales y no sólo leer para hacer un reporte; sino la retroalimentación e interacción es necesaria

Que haya una mayor organización por parte de los profesores, así como también mayor dedicación a los estudiantes. Hacer las clases virtuales por alrededor de 30 o 50 minutos en los que sean verdaderamente efectivos y se discuta el programa establecido. Tratar de hacerlo lo más amigable, tanto para ellos como para nosotros (estudiantes)

Una plataforma con más herramientas

Nada, los maestros fueron demasiado explícitos y comprensibles

Pues que se tuviera una plataforma que todos los alumnos y profesores sepan manejar y tener a la mano los contenidos para leerlos desde casa y dar aportaciones Que todos los profesores utilizarán la misma plataforma y respetarán los horarios

En los relatos anteriores se notan múltiples aspectos a reflexionar, algunos que manifiestan una necesaria reorganización del trabajo docente, la promoción y solicitud de un mayor compromiso por parte del estudiantado, el manejo de herramientas digitales, la dinamización del trabajo síncrono y asíncrono entre el profesorado y el estudiantado, los tiempos dedicados, el compromiso, la escucha y otros más son parte de estos testimonios, en el siguiente apartado dedicado a las conclusiones se reflexiona al respecto.

\section{Conclusiones}

"Narrar se ha adueñado de nosotros, de nuestra vida social y de la comprensión del mundo" (García, 2019), en esta línea de pensamiento las narraciones del estudiantado permiten ver aspectos que en conjunto hablan de una experiencia que lleva a la reflexión sobre lo sucedido en un semestre que comenzó como presencial y concluye en línea, en un contexto que provocó una ruptura profunda e inesperada en la estructura de la UPN. En sus narraciones están los principios para una comprensión de lo sucedido, una posibilidad de aprender y elaborar reflexiones para una acción pedagógica que ayude a sobrepasar situaciones similares en el futuro.

El fenómeno de la pandemia vino a transformar de manera profunda y radical el modo en el que se vivía hasta el momento de su inicio. El confinamiento y el consecuente 
distanciamiento social provocó el abandono de los espacios de convivencia y de las instituciones sociales que, hasta entonces, permitían un encuentro y desencuentro con el otro, en ese contexto el contacto y la interacción presencial cambiaron de ser una posibilidad de reconocimiento del otro a una amenaza a la salud, así es que comienza una fractura en las interacciones humanas al menos como se vivían.

Los escenarios educativos, esos espacios de interacción humana y socialización, hasta que comenzó la pandemia, también eran espacios naturalmente de estudio, donde las mediaciones didácticas se vivían presencialmente y eran parte de una rutina diaria que tanto al profesorado y el estudiantado les permitían elaborar y realizar las estrategias que ayudaran a alcanzar los objetivos de los programas de estudio. La complicidad entre el profesorado y el alumnado cambió no sólo en cuanto al contacto presencial, sino también en esas acciones didácticas que promueven la enseñanza y el aprendizaje.

En la línea de la reflexión didáctica, la pandemia y el confinamiento permitieron ver problemas centrales que antes no estaban a la luz: las brechas tecnológicas y las carencias de recursos para poder realizar estudios en ambientes virtuales y la falta de formación pedagógica y de experiencia para llevar a cabo una enseñanza remota. Cada estudiante que colaboró con esta investigación permitió ver, a partir de sus relatos, las fortalezas y debilidades que se tienen para afrontar problemas de esta naturaleza, algunos puntos a recapacitar son los siguientes:

- La formación pedagógica continua es necesaria, transitar a una didáctica en el marco de una educación en línea y de una enseñanza remota

- Las plataformas virtuales, cada una, ofrece múltiples herramientas para el trabajo docente, sin embargo, es necesario decantar por una y homologar el trabajo académico, de modo que el estudiantado no se confunda y tenga certeza sobre cómo y dónde va a trabajar

- La comunicación es pieza clave en situaciones emergentes como la vivida, ésta permite un ambiente propicio para el aprendizaje, el encuentro y reconocimiento de la otredad y sensibiliza a quienes están involucrados

- Establecer y respetar los tiempos de las sesiones síncronas

- Ofrecer al estudiantado alternativas de trabajo asíncronas que dinamice su actividad y consecuentemente tenga posibilidades para construir su aprendizaje, los foros de discusión, la realización de infografías, diapositivas, videos y podcast pueden ser alternativas verosímiles 
- Contar con la información necesaria que permita ver cuáles son las herramientas tecnológicas que cada estudiante tiene, de modo que éste sea un insumo para la elaboración de la planeación didáctica por parte del profesorado

La UPN en México desde su creación en 1978, ha sido una institución que ha sido fundamental en la formación inicial y continua del magisterio de la educación básica en la historia de esta nación; no obstante, en México no se cuenta aún con una tradición de educación en línea, salvo contadas excepciones, de manera que no es de extrañarse que haya vacíos en la formación de cada docente sobre los fundamentos y las prácticas que sostienen una educación en ambientes virtuales y/o de enseñanza remota. La pandemia enseña que hace falta de ahora en adelante la formación y actualización que coadyuve a un quehacer docente así.

Las plataformas virtuales, aunque bastas y cada una con múltiples posibilidades para el ejercicio docente y para el estudio del alumnado, no son más que herramientas sin sentido sino se cuenta con los conocimientos teóricos y prácticos que les dan sustento, de manera que, con base a los hallazgos en esta investigación, se hace necesario la oferta de programas de capacitación para dotar a la planta docente y también al estudiantado que, como se expresa en algunos de los relatos arriba expuestos, no tienen las competencias para estudiar de tal manera y llegan a caer en la desesperación y el hartazgo.

Las interacciones humanas que se daban en una educación como la que se vivía entes del comienzo de la pandemia, ciertamente se vieron coartadas, de manera que ese componente que dotaba de humanización a los agentes involucrados en los escenarios educativos partir del reconocimiento del otro se suspendió. En la presente investigación, el estudiantado destacó, entre otras cosas, que el contacto y la búsqueda de interacción por parte del docente puede ser un aspecto clave para crear ambientes de enseñanza y aprendizaje productivos que lleven a alcanzar los objetivos de aprendizaje. La comunicación, aun a la distancia, es fundamental en la acción educativa verosímil y que permita lograr los objetivos de los programas, así como perfilar el trayecto escolar del estudiantado hacia el perfil de egreso.

Por otra parte, la experiencia del estudiantado así como los relatos que exponen, permiten ver que en general no hay un rol docente y de estudiante que ayude a cada uno de estos agentes ver de qué modo se puede actuar no, cuáles son las actividades a realizar, las responsabilidades, así como la actividades concretas a llevar a cabo, así como tiempos y 
recursos, menos si se habla de una enseñanza remota, de manera que cuando acontece este tipo de enseñanza se abre la incertidumbre y prevalece la improvisación. El establecer roles docentes y de estudiante permite proyectar las responsabilidades y las acciones que cada cual debe realizar, esto para promover los aprendizajes y el potencial alcance de los objetivos.

El actual contexto pandémico provocó un cambio en la vida de todos y todas, de cada estudiante y cada docente, se dice que estamos en una nueva normalidad, la que nos lleva a una forma diferente de relacionarnos y se develan premisas pedagógicas y didácticas que llevan a una transformación de los escenarios educativos, en palabras de Rodríguez Luna:

Que la actual pandemia cambió el ritmo de nuestras vidas es un hecho innegable, como también lo es que, mientras nuestro espacio físico se estrechó con el confinamiento, nuestro tiempo se expandió y, con ello, pese al miedo y a la incertidumbre, surgieron momentos para nuevas formas de comunicación reflexión. La escuela también entró abruptamente en una nueva normalidad, que puede prolongarse, lo cual demanda acercamientos a lo que ha ocurrido, está ocurriendo y ocurrirá. (2020, p.18)

Ahora, las distintas instituciones educativas, docentes y estudiantes, enfrentan un reto pedagógico que consiste en dosificar programas educativos que desde su realización fueron pensados para ser presenciales, esto lleva a cada involucrado a asumir la responsabilidad que le corresponde y trabajar en realizar los cambios y transformaciones personales que permitan lograr los objetivos de la educación.

La pandemia continua y la educación no se puede detener, ahora se abren preguntas sobre las posibilidades y límites de una educación en línea, en este trabajo las experiencias del estudiantado pueden ser un componente, entre otros, que ayuden a la comprensión de lo que se vive y así poder elaborar propuestas de intervención que ayuden al quehacer educativo y permitan el tránsito a una pedagogía que reflexione sobre aspectos como los que ahora se viven en la actual emergencia sanitaria de proporciones mundiales, la educación ya no es la que era y las experiencias que se viven permiten su entendimiento desde una perspectiva vital y humana. 


\section{Referencias}

Alliaud, Andrea. y Suárez, Daniel. (2011). El saber de la experiencia. Narrativa, investigación y formación docente. Argentina: Editorial CLACSO.

Álvarez, Gabriel. (2019). Construcción y reconstrucción del objeto de estudio en la investigación educativa. Revista Actualidades Investigativas en Educación, 19(3), 1-21. doi: $\underline{\text { https://doi.org/10.15517/aie.v19i3.38795 }}$

Álvarez, Germán. (2020, 16 de Abril). Covid-19. Cambiar de paradigma educativo. Recuperado de $\quad$ http://www.comie.org.mx/v5/sitio/2020/04/16/covid-19-cambiar-de-paradigmaeducativo/

Álvarez, Gabriel. y De la Riva, María. (2021). Experiencias de aprendizaje durante la pandemia Covid-19 en la Universidad Pedagógica Nacional. MENDIVE, 19(2), 379-394. Recuperado de http://scielo.sld.cu/scielo.php?script=sci abstract\&pid=S1815$\underline{76962021000200379}$

Barrios-Tao, Hernando. (2018). Racionalidad narrativa en procesos de investigación-formación en educación. Revista Colombiana de Ciencias Sociales, 9(2), 478-502. doi: https://doi.org/10.21501/22161201.2523

Bolivar, Aantonio., Domingo, Jesús. y Fernández, Manuel. (2001). La investigación biográficonarrativa en educación. Enfoque y metodología. Madrid: Editorial La Muralla,S.A.

Bruner, Jerome. (2002). La fábrica de historias: Derecho, literatura, vida. Argentina: FCE.

Delory-Momberger, Christine. (2009). Biografía y educación. Figuras del individuo-proyecto. Buenos Aires: CLACSO.

García Hernández, Alfonso. (2019). Homo narrator. De cómo contamos historias a lo largo de la vida. Revista científica de la Asociación de Historia y Antropología de los Cuidados, 23(55), 1-10. Recuperado de http://rua.ua.es/dspace/handle/10045/100831

Larrosa, Jorge. (2003). La experiencia de la lectura: estudios sobre literatura y formación. México: FCE.

Mardones, José. y Ursua, Nicanor. (1995). Filosofía de las ciencias sociales y humanas. Materiales para una fundamentación científica. México: Fontamara S.A.

Maykut, Pamela. y Morehouse, Richard. (1999). Investigación cualitativa. Una guía práctica y filosófica. Barcelona: Hurtado ediciones.

Niño, Shamaly., Castellanos, Juan. y Patrón, Felipe. (2021). Contraste de experiencias de estudiantes universitarios en dos escenarios educativos: enseñanza en línea vs. enseñanza remota de emergencia. RED. Revista de Educación a Distancia, 21(65), 1 24. doi: https://doi.org/10.6018/red.440731 
Pérez de Lara, Nuria. (2011). Escuchar al otro desde sí. En C. Skliar \& J. Larrosa (Comp.), Experiencia y alteridad en educación (pp. 45-77). Rosario, Argentina: Homo Sapiens Ediciones.

Rodriguez, Gregorio., Gil, Javier. y García, Eduardo. (1996). Metodología de la investigación cualitativa. Málaga: Ediciones Aljibe, S.L.

Rodríguez Luna, María. (2020). Potencia del lenguaje en tiempos de pandemias [separata]. Enunciación, 25(2), 17-21. doi: https://doi.org/10.14483/22486798.16299

Skliar, Carlos. (2020). Subrayar y narrar, mientras respiramos. Enunciación, 25(2), 5-8. doi: https://doi.org/10.14483/22486798.17013

Skliar, Carlos. y Larrosa, Jorge. (2009). Experiencia y alteridad en educación. Argentina: Homo Sapiens Ediciones.

Van Manen, Max. (1998). El tacto de la enseñanza. El significado de la sensibilidad pedagógica. Barcelona: Ediciones Paidos Ibérica, S.A.

Van Manen, Max. (2003). Investigación educativa y experiencia vivida: Ciencia humana para una pedagogía de la acción y la sensibilidad. Barcelona: Idea Books, S.A. 


\section{Anexos}

\section{Anexo 1.}

\section{Preguntas primer cuestionario}

- ¿Trabajas actualmente? No importa si es formal, informal o un trabajo esporádico

- En general ¿Qué tan difícil ha sido para ti hacer tus aprendizajes, a distancia, en este contexto de la pandemia COVID-19?

- A tu respuesta a la pregunta anterior, describe ampliamente por qué.

- ¿Cuáles han sido las mayores dificultades que has vivido hasta ahora para poder llevar a cabo tus clases y tus aprendizajes? Describe ampliamente.

- En general ¿Cómo han sido tus clases a distancia hasta ahora?

- En general ¿Cómo crees que pudieran ser mejor tus clases a distancia?

- ¿Qué podrías sugerir para mejorar tu experiencia pedagógica en este contexto de las clases A Distancia?

- Por favor, deja algún comentario que tenga que ver con tu experiencia en este contexto de la educación a distancia consecuencia de la pandemia COVID-19. 


\section{Anexo 2.}

\section{Preguntas segundo cuestionario}

- ¿Trabajas actualmente? No importa si es formal, informal o un trabajo esporádico

- ¿Con qué dispositivos tecnológicos cuentas y que realmente te sean útiles para tus clases a distancia? (Puedes marcar más de uno)

- A partir de tus recursos tecnológicos con los que cuentas y que marcaste en tu respuesta anterior, ¿Qué tan difícil ha sido para ti tu experiencia de aprendizaje?

- A partir de tu respuesta anterior, describe ampliamente, por favor.

- ¿Cómo te conectas a internet para atender las clases que recibes a distancia?

- ¿Tu conexión a internet ha representado para ti un obstáculo en tus clases a distancia? A partir de tu respuesta anterior, explica ampliamente por qué

- A partir de tu experiencia de aprendizaje a distancia provocada por la pandemia del COVID-19 ¿Los recursos tecnológicos y tu acceso a internet han sido un obstáculo? Describe ampliamente, por favor.

- ¿Qué programas y/o aplicaciones utilizan tus profesores para el trabajo en línea? (Puedes marcar más de una)

- ¿Con qué frecuencia ocupan tus profesores Correo Electrónico para sus clases?

- Describe cómo ocupan tus profesores Correo Electrónico para sus clases

- ¿Con qué frecuencia ocupan tus profesores Whatsapp para sus clases?

- Describe cómo ocupan tus profesores whatsapp para sus clases

- ¿Con qué frecuencia ocupan tus profesores Faceebook para sus clases?

- Describe cómo ocupan tus profesores Facebook para sus clases

- ¿Con qué frecuencia ocupan tus profesores Zoom para sus clases?

- Describe cómo ocupan tus profesores Zoom para sus clases

- ¿Con qué frecuencia ocupan tus profesores Skype para sus clases?

- Describe cómo ocupan tus profesores Skype para sus clases

- ¿Con qué frecuencia ocupan tus profesores Twitter para sus clases?

- Describe cómo ocupan tus profesores Twitter para sus clases

- ¿Con qué frecuencia ocupan tus profesores Blogs para sus clases?

- Describe cómo ocupan tus profesores Blogs para sus clases 
- ¿Con qué frecuencia ocupan tus profesores Blackboard para sus clases?

- Describe cómo ocupan tus profesores Blackboard para sus clases

- ¿Con qué frecuencia ocupan tus profesores Moodle para sus clases?

- Describe cómo ocupan tus profesores Moodle para sus clases

- ¿Con qué frecuencia ocupan tus profesores Google Scholar para sus clases?

- Describe cómo ocupan tus profesores Google Scholar para sus clases

- ¿Con qué frecuencia ocupan tus profesores Microsoft Teams para sus clases?

- Describe cómo ocupan tus profesores Microsoft Teams para sus clases

- ¿Con qué frecuencia ocupan tus profesores Hangouts para sus clases?

- Describe cómo ocupan tus profesores Hangouts para sus clases

- Haciendo un balance general ¿Qué tan frecuente es el acercamiento de tus profesores hacia ti y tu grupo para atender las clases?

- Explica tu respuesta anterior

- Desde tu experiencia personal ¿Qué tan difícil ha sido para ti hacer tus aprendizajes, a distancia, en este contexto de la pandemia COVID-19?

- ¿Cómo han sido tus clases a distancia hasta ahora?

- ¿Cómo crees que pudieran ser mejor tus clases a distancia?

- ¿Qué podrías sugerir para mejorar tu experiencia pedagógica en este contexto de las clases A Distancia?

- Por favor, deja algún comentario que tenga que ver con tu experiencia en este contexto de la educación a distancia consecuencia de la pandemia COVID-19. 


\section{Anexo 3.}

\section{Guion de entrevista conversacional}

\section{"Experiencias de aprendizaje en las licenciaturas escolarizadas en Pedagogía y Psicología Educativa en la Universidad Pedagógica Nacional." \\ Entrevista conversacional}

Nombre:

Edad: lugar y fecha de nacimiento:

Licenciatura:

¿Con quién vives?

Semestre que cursó en el 2020-1:

¿Por qué decidiste estudiar esta carrera? Ocupación de padres o tutores:

Presentación: A continuación se expone un guion de entrevista conversacional con el cuál pretendemos captar los relatos que den cuenta de mi experiencia como estudiante de licenciatura, narrando aspectos del aprendizaje en el contexto de la pandemia covid-19; lo anterior narrado en primera persona, relatando sucesos específicos y que para mí son dignos de ser rememorados.

Criterios y principios de trabajo:

- Investigamos juntos un fenómeno de la vida: ser estudiante de licenciatura en el contexto de la pandemia covid-19

- Vamos a conversar sobre mi experiencia tomando como punto de partida primordialmente mis actividades de aprendizaje en el contexto ya señalado, aunque abordaremos también otros temas

- Buscamos saberes, sentidos y significados como elementos sustantivos de la noción de ser estudiante

- Mis relatos tienen que ser tal cual los recuerdo, los viví, utilizando una narrativa que permita a mis interlocutores vivir imaginativamente lo que yo viví, considerando que las experiencias son pre reflexivas.

Algunas sugerencias para describir mi experiencia

- Tengo que describir mi experiencia a partir de relatos, estos a saber son:

[...] narración (retrospectiva) por el propio protagonista de su vida o de determinados fragmentos/aspectos de ella, por iniciativa propia o a requerimiento de uno o varios interlocutores. En este caso la historia de vida es tal y como la cuenta la persona que la vivió (Bolivar, Domingo, \& Fernández, 2001).

- Hay que evitar tanto como sea posible las explicaciones causales, las generalizaciones, o las interpretaciones abstractas. Por ejemplo, no es de ninguna ayuda saber qué fue lo que «provocó» una determinada reacción mía o de quien coprotagoniza la experiencia, por qué «razones» se da un suceso o «cómo»o «qué» podría pasar.

- Describir mi experiencia desde adentro por así decirlo, esto es: concentrándome en los detalles del lugar como los recuerdo, mis sensaciones corporales y apreciaciones sentimentales, estados de ánimo, personas que se involucran, mi percepción del tiempo, etcétera.

- Me tengo que concentrar en un ejemplo o suceso particular del objeto de mi experiencia, es decir, describir hechos específicos: una aventura, un acontecimiento, un evento, una contingencia, una experiencia concreta, una clase, etc.

- Intentaré concentrarme en un ejemplo de la experiencia que se destaque por su intensidad, como si fuera la primera vez que lo vivo.

- En la narración de mi experiencia tengo que concentrarme en mi cuerpo, el espacio donde fue, mis relaciones con el tiempo y en el papel que los otros tuvieron dentro de ésta.

- Tengo que evitar embellecer el relato con frases hermosas o terminología rimbombante. Ejes temáticos:

1. Mi historia de vida, de dónde vengo, cuáles son mis raíces, los orígenes de mis padres y ocupación

2. Mi situación actual, dónde y con quién vivo, a qué me dedico

3. Cómo viví el tránsito de mis estudios presenciales a una modalidad a distancia, en el contexto covid-19, qué dificultades viví, cómo las afronté (Ver cuestionario)

4. Cómo fueron mis clases y qué estrategias ocuparon mis profesores

5. Otros temas

Fin de la entrevista

¡Gracias! 
Revista indizada en

scip/o redalyc satindex

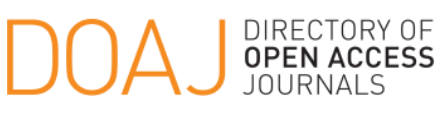

Distribuida en las bases de datos:
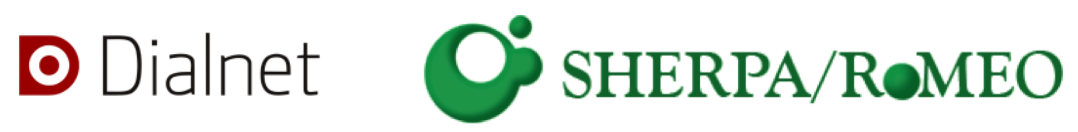

REDIB

Red Iberoamericana

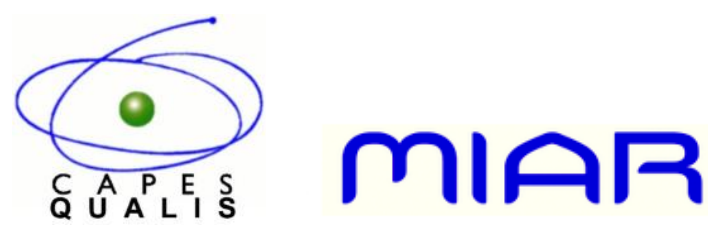

